\title{
Semantic facilitation without association in a lexical decision task
}

\author{
IRA FISCHLER \\ University of Florida, Gainesville, Florida 32611
}

\begin{abstract}
Subjects were shown pairs of letter strings and had to decide as quickly as possible whether both strings were words. The word pairs included associates (e.g., cat-dog), words not normatively associated that had been rated by other subjects as semantically similar (e.g., nurse-wife), and unrelated control pairs (e.g., bread-stem). Both associates and semantically related pairs were responded to more quickly than were the corresponding control pairs. The magnitude of the facilitation for the associates appeared to be related more to the semantic similarity ratings than to measures of either direct or indirect associative strength. It was concluded that the encoding of a word can be facilitated by the prior processing of a semantically related word.
\end{abstract}

In a lexical decision task, the subject is asked to decide whether or not a given stimulus is a word. Meyer and Schvaneveldt (1971) have shown that latency to decide that two presented items were both words was shorter if the second word was a primary associate of the first, as with the pair "bread-butter." For a number of reasons, this association effect has been influential in recent elaborations of semantic memory theory. First, the task is at least nominally a lexical rather than a semantic one, and the subject is not asked to access the meaning of the words, or to compare the words in any way. Fodor, Bever, and Garrett (1974) have criticized the use of semantic decision tasks to investigate semantic memory, arguing that data from such tasks may be constrained more by the procedures used than by the structure of semantic memory. By analogy, one could sort words into those ending in vowels vs those ending in consonants, but this would not mean that the lexicon is organized along this dimension. The use of an apparently nonsemantic task avoids this difficulty.

Second, it appears that the effect is produced at the encoding stage, since degrading the stimulus display increases the size of the facilitation (Meyer, Schvaneveldt, \& Ruddy, 1975). This finding would also seem to minimize the role of task constraints, as well as any verification processes which might follow stimulus encoding (cf. Collins \& Loftus, 1975). Third, the facilitation seems to be produced more by what Posner and Snyder (1975) have called "automatic" processes than by attention or expectancy. Associates are responded to more quickly than are nonassociates whether the two words are presented simultaneously

We wish to thank Jon Muntz for collecting the data for this study, and Richard Griggs, Don Keen, and Larry Osterman for comments on an earlier version of the paper. This research was supported in part by a grant from the University of Florida Behavioral and Social Sciences Institute. or successively (Meyer, Schvaneveldt, \& Ruddy, Note 1), and when subjects are given only a single associate after a series of unrelated items (Fischler, 1977; cf. Neeley, in press). Finally, the facilitation is maintained when the second item is presented only $100 \mathrm{msec}$ after the first, and the subject has only to respond to the second item (Fischler, Note 2). This rapid onset is another characteristic of automatic facilitation, according to Posner and Snyder (1975).

The effect of association on lexical decision time would thus appear to provide an excellent framework for investigating the role of the semantic relations between words. In fact, Meyer et al. (1975) referred to the facilitation as one produced by a "semantic context," and explained the effect in terms of activation spreading from the node in semantic memory corresponding to the first word of the pair, to the node corresponding to the second, increasing its availability. The concept of an automatic spread of activation, originally described by Quillian (1962), has been incorporated into several recent models of the human memory system, notably Anderson (1976) and Collins and Loftus (1975).

Although a semantic interpretation of the facilitation has been generally accepted, a consideration of the stimuli used in these experiments suggests an alternative explanation. Associates, by definition, are items which occur as stimulus-response pairs when subjects are asked to respond to one word with another word. Commonly, these associative links have been viewed as one manifestation of the more basic semantic relations between the items (e.g., Clark, 1970; Collins $\&$ Loftus, 1975). But it has long been understood that such associations between words could arise both from semantic properties of the words themselves and from accidents of contiguity. Wundt, for example, distinguished between "inner" associations, which were based on semantic and logical relationships between words, and "outer" associations based on 
contiguity and speech habits (Esper, 1973, p. 98). It is possible, then, that some or all of the facilitation produced in the lexical decision task is a result of the "accidental" association between two items, rather than any underlying semantic relationship between them.

Implicit attempts to distinguish various aspects of association between items in semantic judgment tasks have included work on the role of category size (e.g., Landauer \& Meyer, 1972) and of property frequency (e.g., Conrad, 1972), which roughly correspond to manipulations of associative value and associative strength, respectively. In nonsemantic tasks, the only notable effort to distinguish semantic from accidental factors in association has been in extensions of Underwood's (1965) false-recognition effect. In the paradigm experiment, Underwood (1965) found that false alarms to a word such as "white" could be made more likely by the repeated prior presentation of an associate such as "black" in a continuous recognition task. A number of recent studies have used synonyms, antonyms, and other associates in a false-recognition paradigm, and controlled for associative strength across the three types of associates. Synonyms typically produce a higher rate of false alarms than do other types of associates (Anisfeld \& Knapp, 1968). Fillenbaum (1969) also found a sizable increase in false alarms for antonyms. Other studies, however, have shown the antonym effect to be unreliable (Grossman \& Eagle, 1970). Also, Elias and Perfetti (1973) obtained results which seem to contradict the false alarm effect for synonyms: When subjects were explicitly instructed to think of synonyms to each test word, false alarms to synonyms actually presented later in the series were no more frequent than to control words. In fact, the instructions produced better overall performance compared to a group receiving no instructions. These results suggest that the false-recognition effects reflect a good deal more than the automatic activation of responses.

The procedure of controlling for associative factors by equating associative strength in the above studies also creates several problems. While Grossman and Eagle (1970) found that associative strength was unrelated to false alarm rate, Mueller, Yadrick, Pavur, and Adkins (1975) reported a significant effect of associative strength within each of their word classes. Since there are apparently consistent differences between associative strength measures obtained in the usual normative fashion and that obtained in the context of an experimental session (Cramer, 1969), and since synonyms and antonyms are associated as well as semantically related, it would seem that the presence of any direct associative strength between the critical items would make interpretation of false alarm rates difficult.

Given that the role of associative strength in these tasks is difficult to assess, a clear alternative is to eliminate direct associative strength altogether from a set of stimuli. In the present experiment, therefore, stimulus pairs were constructed in which the two words were not normatively associated, but had some degree of semantic similarity. For example, the word "wife" does not occur as an associate to the stimulus word "nurse," but the words are clearly more similar semantically than are "nurse" and "mine." This similarity can be characterized as a sharing of a number of semantic features (Katz \& Fodor, 1963; Smith, Shoben, \& Rips, 1974), such as [thuman], [-male], or as a certain amount of interlinking of the two corresponding nodes in a semantic network (Collins \& Loftus, 1975). If these features or links are a functional aspect of the encoding of a word, then the encoding of "nurse" should make analysis of "wife" proceed more quickly, despite the absence of any tendency for "nurse" to directly elicit "wife" as an associate. Thus, finding a significant facilitation for pairs like "nursewife" in the double lexical decision task would support a semantic interpretation of the facilitation initially described by Meyer and Schvaneveldt (1971).

A set of associates was also included in the experiment in order to insure that the facilitation could be replicated under the conditions of presentation employed. Moreover, since the associates were selected over a range of primary associate strengths, the correlations of both associative strength and semantic similarity with the size of the facilitation could be assessed. It was thought that, since the facilitation could well be due to both semantic and "accidental" factors, either or both of these measures might correlate with the reduction in latency.

\section{METHOD}

\section{Subjects}

Twenty-four undergraduates at the University of Florida participated in the experiment as a part of the introductory psychology course requirements.

\section{Apparatus}

An Iconix tachistoscope and four-field exposure box were used to present the stimuli and record latencies. Three telegraph keys located near the subject's right hand were arranged in a small arc, with about $3 \mathrm{~cm}$ between each key. During a trial, the subject would rest the forefinger of his right hand on the center key, and respond by moving that finger left or right to depress the appropriate outer key.

\section{Stimulus Materials}

Thirty-two pairs of words were compiled which were judged by the experimenter to be semantically related without being associated (SR pairs). To confirm this, two stages of normative analysis were carried out. In the first stage, a written free association test was given to 40 graduate students in the psychology department of the university. The test consisted of the first members of the SR pairs, along with 16 other words which seemed likely to have dominant primary responses. All words used were of either one or two syllables, three to six letters long, and had a frequency of occurrence in the Kucera and Francis (1967) count of at least 10. Each student was given a booklet containing the stimulus words, four to a page, and was instructed to write down the first three words that came to mind for each stimulus word.

The primary responses to the 16 additional words ranged 
Table 1

Mean Semantic Similarity Ratings for Associates (AR), Semantically Related Pairs (SR), and Control Pairs

\begin{tabular}{lcc} 
Pair Type & $\begin{array}{c}\text { Mean Rating } \\
(\mathrm{n}=40)\end{array}$ & SD \\
\hline AR & 5.1 & 1.1 \\
SR & 3.8 & .7 \\
Control & 1.4 & .3 \\
\hline
\end{tabular}

in probability of occurrence (per subject) from .18 to .73. These words and their primary responses served as the associatively related pairs (AR pairs) in the experiment. The probability of occurrence for the second word of each SR pair was zero; that is, the second words never occurred as associative responses in this sample.

In the second stage of analysis, ratings of semantic similarity were obtained as follows: The $32 \mathrm{SR}$ pairs, the $16 \mathrm{AR}$ pairs, and 32 unrelated pairs of words were presented to each of 40 graduate students from the English department, with the following instructions: "Look at each pair of words on this list and judge to what extent the meaning of the two words seems to you to share any aspects or characteristics. Use a rating scale from 1 to 7 , with 1 indicating no overlap, and 7 , complete overlap." The SR pairs were reliably rated as more similar than the unrelated pairs. The AR pairs produced the highest ratings, although a number of them were rated below the mean of the SR-pair ratings. For example, the average rated similarity of "jump-rope" was 3.1. The mean ratings are shown in Table 1.

The higher ratings for AR pairs did not present a problem, since the logic of the experiment required only that the SR pairs show some facilitation over control pairs, and not that this effect be equal to that found for AR pairs. Still, since a higher rating might increase the probability of obtaining a significant facilitation, the 16 SR pairs which had been given the highest mean rating were used as stimuli in the experiment. The SR and AR pairs used are listed in the Appendix. The two measures for the AR pairs were uncorrelated $(r=+.01)$.

In addition to direct associative strength, a second method of assessing associative relations was employed for the $S R$ and AR pairs. Although "nurse" and "wife" were not directly associated, it was possible that they had many common associates, such as "woman." While the SR pairs were initially selected to minimize such common associates, their presence in any significant amount might produce as strong a facilitation as that produced by a single, direct associative link. Therefore, a second free association test was given to a different set of 40 psychology graduate students. The test consisted of the second items of both the SR and AR pairs. Again, three responses were obtained from each student for each word. A modified version of Jenkins and Cofer's (1957) Index of Mutual Relatedness (MR) was used to assess the degree of associative relatedness between the words of each pair. In the present version, $M R=\Sigma R c /(4 n / 3)$, where $R c$ is the number of times a given word occurred as a response to both stimuli (e.g., "woman" to both "nurse" and "wife"), and $n=$ the total number of responses obtained for each word. For the SR pairs, the mean relatedness was .07 . In contrast, the mean relatedness of the AR pairs was .25 .

Unrelated word pairs (SU and $\mathrm{AU}$ ) were generated by switching the second words of two pairs within each type, such that word length and spelling patterns were preserved as closely as possible; for example, "wife" and "mine" were exchanged. This allowed the same words to be used in both the experimental and control pairs across subjects. $A$ set of 32 new pairs was used to generate the nonword stimuli by replacing a single letter in one or both of the words with another letter of the same type; thus, "drip-louse" became "drap-loase" in the nonword-nonword condition. Each pair of items was typed in black capital letters on a $15 \times 23 \mathrm{~cm}$ white card with an IBM Executive Registry typewriter, such that it would appear in the center of the viewing area of the exposure field. A pair subtended a visual angle of approximately $1 \mathrm{deg}$ both horizontally and vertically.

\section{Design}

Each subject saw half of the pairs from each of the four groups of pair types, giving a total of 32 positive trials. Pairs were assigned to subjects by means of an incomplete blocks design, such that a given pair of subjects saw all the word pairs, and no subject saw any one word more than once. Within each pair of subjects, the division of stimuli into experimental and control pairs was random.

There were 32 negative trials in each session, consisting of approximately equal numbers of word-nonword, nonword-word, and nonword-nonword pairs. The order of presentation of pairs within a session was random, with the constraint that there be no more than four consecutive positive or negative trials.

\section{Procedure}

Subjects were tested individually in a single session that lasted about $30 \mathrm{~min}$. At the start of each session, the subject was told that on each trial she would be shown a pair of letter strings, and that the task was to decide if both strings were words and to indicate their response manually as quickly as possible. Nothing was said about the relationship between words in some of the pairs.

On each trial, a fixation point consisting of a small cross appeared for $500 \mathrm{msec}$. The cross was located slightly above and to the left of the upper item of the subsequent pair. This was replaced by the stimulus, which remained on until one of the response keys was depressed. Latency was recorded, errors noted, and the next trial was begun. There was approximately $15 \mathrm{sec}$ between trials. For half the subjects, the right key was used to indicate a positive response; for the remaining subjects, the left key was positive.

\section{RESULTS}

The mean latency for correct responses was calculated across 12 subjects for each word pair. The mean latency for each pair type is presented in Table 2 , along with the standard deviation across pairs, and the error rates. It can be seen that both $S R$ and $A R$ pairs tended to produce shorter latencies than did the corresponding control pairs. A preliminary ANOVA treating the means for each pair as a single score was performed on the latency data. The related pairs were responded to more quickly than were control pairs $[F(1,60)=6.40, p<.03]$. Pairs in the two semantic conditions (SR and SU) produced longer latencies than

Table 2

Mean Latency (in milliseconds), Error Rates, and Standard Deviations for Associates (AR), Semantically Related Pairs (SR), and Control Pairs (AU and SU)

\begin{tabular}{cccrc}
\hline Pair Type & Latency & Error Rate & \multicolumn{1}{c}{ SD } & Net Facilitation \\
\hline AR & 809 & $.0 \%$ & 73 & \\
AU & 908 & $1.0 \%$ & 90 & $99 \mathrm{msec}$ \\
S R & 875 & $.5 \%$ & 82 & $84 \mathrm{msec}$ \\
S U & 959 & $4.7 \%$ & 119 & \\
\hline
\end{tabular}


did pairs in the associative conditions $[F(1,60)=15.40$, $p<.01]$. but there was no interaction between relatedness and pair types $[F(1,60)<1.00]$.

Separate ANOVAs were then performed on the raw scores for the semantic condition and for the associative condition. Each pair of subjects was treated as one level of a "subject-pair" factor in a mixed factorial design with subject pairs crossed with relatedness. In order to test the significance of the relatedness factor over subject- and word-pair domains concurrently, a "quasi-F" ratio was derived (Clark, 1973). treating both factors as random variables. For the associative condition. the AR pairs were responded to significantly faster than were the $A U$ pairs $\left[F^{\prime}(1,41)=7.98, p<.01\right]$. Likewise, the latencies for $S R$ pairs were faster than those for $S U$ pairs $\left[F^{\prime}(1,41)=4.86, p<.05\right]$.

Correlational analyses of the data were limited to the AR pairs. since by design the normative values for the relational properties of the SR pairs were either zero (for normative associative strength), near zero (for mutual relatedness), or of very low variability (for semantic similarity ratings). While none of the correlations reached significance, only the semantic similarity ratings tended to correlate positively with the size of the facilitation $(r=+.31)$. Direct associative strength was negatively correlated with the size of the facilitation $(\mathrm{r}=-.38)$. Mutual relatedness, which presumably reflects a more complete assessment of associative relation, produced a correlation which was essentially zero $(r=-.01)$.

The latency data for negative trials was examined for trends similar to those found in previous investigations. Mean latency for correct negative responses was longer overall than that for positive responses. Latency in the word-first condition (UN pairs) was substantially longer $(1,159 \mathrm{msec})$ than for either NU pairs $(981 \mathrm{msec})$ or NN pairs $(961 \mathrm{msec})$. This was true for every subject. Error rate for UN trials $(12 \%)$ was also higher than that for NU trials (2\%) or NN trials (3\%). This general pattern of data is consistent with the serial decision model des̀cribed by Meyer and Schvaneveldt (1971).

\section{DISCUSSION}

The present results support a semantic interpretation of the facilitation reported by Meyer and Schvaneveldt (1971). Facilitation in a double lexical decision task was found for pairs of words which shared no direct associative relationship, as measured by normative procedures, but which had been judged as semantically similar. Moreover, the degree of semantic similarity for associates appeared to have a greater effect on the size of the facilitation than did the strength of the association per se. ${ }^{1}$ Extending the definition of association to include mutual associates of the two words of a pair had little effect. The rarity of such mutual associations within the SR pairs, and the failure of the mutual relatedness index to correlate with the size of the facilitation for the AR pairs. make an explanation of the effect for SR pairs in terms of mediated associations of the sort obtained in free association tasks seem dubious.

The range of latencies and the size of the facilitation for both the AR and SR pairs are quite close to those found in earlier studies. The somewhat larger and more reliable facilitation for the AR pairs may be due to the higher average semantic similarity for these items. Since previous work has suggested that the locus of facilitation is in the encoding of the second word of the pair, it may be concluded that the encoding of a word can be facilitated by the prior processing of a semantically related word.

That semantic relatedness can influence the encoding of words in the absence of direct association does not mean that the facilitation observed is not ultimately based on associative links which were at one point episodically derived. Whether one speaks of a semantic network (e.g.. Collins \& Loftus. 1975) or an "analytic" model which differentiates words into component parts or features (e.g.. Smith et al., 1974), the pattern of associative links between nodes in the network or between a concept and its component features is assumed to be the mechanism through which the present priming effect occurs. Semantic facilitation can thus be interpreted as the priming of features, or as the spread of activation through a semantic network. Collins and Loftus (1975) suggest that the greatest priming effect will be found between concepts and their property nodes (e.g., "rose-red") and between concept nodes which are highly crosslinked in the network (e.g., "car-truck"). While some of the SR pairs do seem to be part of the same conceptual class (e.g., "tablestool"), others do not (e.g., "glass-ice." "coat-shell"). It may be, then, that the spread of activation through the semantic space is more pervasive than previously thought. Further research with a greater variety of SR pairs distributed over the entire range of semantic relatedness would be necessary to explore the boundary conditions of the priming effect (cf. Anderson, 1976, for a discussion of possible mechanisms for limiting the spread of activation through a network).

Although most interpretations of semantic priming are understandably in terms of verbal processes, there has been at least one demonstration (Rosch, 1975) that pictures may allow more efficient semantic priming than do words. In view of recent work directed toward distinguishing verbal from visual processing, one might be tempted to explain the facilitation for SR pairs in terms of visual imagery. The images evoked by the respective words within an SR pair are often similar. For example. a nurse may look very much like a wife. Producing an image corresponding to the first word in the pair may then facilitate processing of the second word. The major difficulty with such an interpretation is the speed of the double lexical decision, typically less than $1 \mathrm{sec}$. Latency for reporting images to words. in contrast, is on the order of 2 to $3 \mathrm{sec}$ (Paivio, 1966). 
which would appear to be too slow to be a factor in the present task. On the other hand, if it is argued that the semantic information used in constructing such images (e.g., typical size, shape, etc.) is part of the source of the facilitation, then there seems to be no inconsistency with the present notion of priming through semantic activation.

\section{REFERENCE NOTES}

1. Meyer, D. E., Schvaneveldt, R. W., \& Ruddy, M. G. Activation of lexical memory. Paper presented at the meeting of the Psychonomic Society, St. Louis, Missouri, November 1972.

2. Fischler, I. Latency of associative facilitation in a lexical decision task. Unpublished manuscript, 1975. (Available from Ira Fischler, Psychology Department, University of Florida, Gainesvilie, Florida 32611.)

\section{REFERENCES}

Anderson, J. R. Language, memory, and thought. Hillsdale, N.J: Lawrence Erlbaum, 1976.

ANISFELD, M.. \& KNAPP, M. Association, synonymity, and directionality in false recognition. Joumal of Experimental Psychology, 1968, 77, 171-179.

ClaRK, H. H. Word associations and linguistic theory. In $J$. Lyons (Ed.). New horizons in linguistics. Baltimore, Md: Penguin, 1970.

Clark, H. H. The language-as-fixed-effect fallacy: A critique of language statistics in psychological research. Journal of Verbal Learning and Verbal Behavior, 1973, 12, 335-359.

Collins, A. M., \& Loftus, E. F, A spreading-activation theory of semantic processing. Psychological Review, $1975,82,407-428$.

Conrad, C. Cognitive economy in semantic memory. Journal of Experimental Psychology, 1972, 92, 149-154.

Cramer, P. The determinants of mediated priming: Time interval, semantic and associative relationships. Journal of Verbal Learning and Verbal Behavior, 1969, 8, $266-271$.

Elias. C. S., \& Perfetti, C. A. Encoding task and recognition memory: The importance of semantic encoding. Journal of Experimental Psychology, 1973, 99, 151-156.

ESPER. E. A. Analogy and association in linguistics and psychology. Athens, Ga: University of Georgia Press, 1973.

Fillenbaum, S. Words as feature complexes: False recognition of antonyms and synonyms. Journal of Experimental Psychology, 1969, 82, 400-402.

Fischler, I. Expectancy and associative facilitation in a lexical decision task. Joumal of Experimental Psychology: Human Perception and Performance, 1977, 3, 18-26.

Fodor, J. A., BEVER, T. G., \& GARRETT, M. F. The psychology of language: An introduction to psycholinguistics and generative grammar. New York: McGraw-Hill, 1974.

Grossman, L., \& Eagle, M. Synonymity, antonymity, and association in false recognition responses. Journal of Experimental Psychology, 1970, 83, 244-248.

Jenkins, P. M., \& COFER, C. N. An exploratory study of discrete free association in compound verbal stimuli. Psychological Reports, 1957, 3, 599-602.

KATZ, J. J., \& Fodor, J. A. The structure of a semantic theory. Language, 1963, 39, 170-210.

Kućera, H., \& Francis, W. N. Computational analysis of present day American English. Providence, R.I: Brown University Press, 1967.

LaBerge, D. Perceptual learning and attention. In $\mathbf{W} . \mathbf{K}$.
Estes (Ed.), Handbook of learning and cognitive processes: Attention and memory (Vol. 4). Hilisdale, N.J: Lawrence Erlbaum, 1976.

Landauer, T. K., \& Meyer, D. E. Category size and semantic memory retrieval. Journal of Verbal Learning and Verbal Behavior, 1972, 11, 539-549.

MeYer, D. E., \& SchVaneveldt, R. W. Facilitation in recognizing pairs of words: Evidence of a dependence between retrieval operations. Joumal of Experimental Psychology, 1971, 90, 227-234.

Meyer, D. E., Schvaneveldt, R. W., \& Ruddy, M. G. Loci of contextual effects in visual word recognition. In $P$. Rabbitt (Ed.), Attention and performance $V$. New York; Academic Press, 1975.

Mueller, J. G., Yadrick, R. M., Pavur, E. J., \& Adkins, C. The effects of instructions on false recognitions. American Journal of Psychology, 1975, 88, 65-75.

Neeley, J. H. Semantic priming and retrieval from lexical memory: The roles of inhibitionless spreading activation and limited-capacity attention. Journal of Experimental Psychology: General, in press.

Parno, A. Latency of verbal associations and imagery to noun stimuli as a function of abstractness and generality. Canadian Journal of Psychology, 1966, 20, 378-387.

PosNer, M. I., \& SNYDER, C. R. Attention and cognitive control. In R. L. Solso (Ed.), Information processing and cognition. Hillsdale, N.J: Lawrence Erlbaum, 1975. Pp. 55-85.

Quillian, M. R. A revised design for an understanding machine. Mechanical Translation, 1962, 7, 17-29.

Rosch, E. Cognitive representations of semantic categories. Journal of Experimental Psychology: General, 1975, 104, 192-233.

Smith, E. E., Shoben, E. J., \& Rips, L. J. Structure and process in semantic memory: A featural model for semantic decisions. Psychological Review, 1974, 81, 214-241.

UNDERWOOD, B. J. False recognition produced by implicit verbal responses. Joumal of Experimental Psychology, $1965,70,122-129$.

\section{NOTE}

1. It also appears that association without semantic relations has no effect on lexical decision time. An attempt in our laboratory to produce the facilitation by having subjects learn a list of paired associates prior to the lexical decision task was unsuccessful. However, since the paired associates were learned only to a simple performance criterion, it remains possible that training sufficient to produce the characteristics of "automatic" association (cf. LaBerge, 1976) would produce a facilitation to the lexical decision task.

(Received for publication November 19, 1976; revision accepted January $28,1977$. )

Appendix

Word Pairs Used in the Experiment

\begin{tabular}{llll}
\hline \multicolumn{2}{c}{ Semantically } & Related Pairs & \multicolumn{2}{c}{ Associates } \\
\hline bread-cake & tree-stem & hurt-pain & horn-blow \\
table-stool & dish-tray & ground-dirt & room-space \\
knife-saw & dance-skate & road-street & watch-time \\
cave-mine & grass-hair & lock-key & jump-rope \\
bath-swim & stove-torch & dream-sleep & wine-red \\
team-staff & glass-ice & shave-razor & ranch-house \\
boy-prince & coat-shell & arm-leg & fist-hand \\
fog-gas & nurse-wife & cat-dog & sugar-sweet \\
\hline
\end{tabular}

